are as follows : 1. J. A. Macwilliam, M.D., Professor of Physiology, with A. H. Mackie, M.D., and Charles Marray, M.D., Assistants in Physiology in the University of Aberdeen, on the Intravascular Injection of Salts and of Nacleo-proteid, with 14 figures in the text. Tracings are given showing the effect of the intravascular injection of various sodium salts on the respiration. The exophthalmos which has long been known to follow the injection of nucleo-proteid obtained from the thymus or from lymph glands is shown in this article to be due to blood clots at the back of the orbits. 2. Otto May, M.D., on the Relationship of Blood-supply to Secretion with especial Reference to the Pancreas, with nine figures in the text. Dr. May finds that there is no direct relationship between the rate of secretion of pancreatic juice and the amount of its blood-supply. Secretion continues for some time after complete cessation of the pancreatic secretion. He also finds that the pancreas is well supplied with vaso-constrictor nerves which in the cat proceed from the solar plexus in the bundle of postganglionic fibres accompanying the cœliac axis artery. 3. W. M. Fletcher, the Osmotic Properties of Muscle and their Modifications in Fatigue and Rigor, with 11 figures in the text. 4. J. N. Langley, F.R.S., and H. K. Anderson, on the Union of the Fif $i$ Cervical Nerve with the Superior Cervical Ganglion. The experiments of the authors of this article lead them to conclude that certain somatic fibres are capable in favourable circumstances of making functional connexion with sympathetic nerve-cells. 5. Keith Lucas, on the Intluence of Tension upon the Contraction of Skeletal Muscle at High Temperatures, with five figures in the text. 6. E. G. Wilcock, the Action of the Rays from Radium upon some Simple Forms of Animal Life. 7. Major R. H. Elliot, M.B, and E. Burnett, B A, a Modification of Professor Schäfer's Frog-heart Plethysmograph, with some observations on the mode of using it, with one figure in the text. 8. $R$ Row, M.D., on Some Effects of the Constituents of Ringer's Circulating Fluid on the Plain Muscle of Rana Tigrina, with 15 figures in the text. 9. T. G. Brodie, M.D., and W. E. Dixon, M.D., Contributions to the Physiology of the Lungs, with 10 figures in the text. This article is occupied with the consideration of the vaso motor nerves of the lung. The authors give the results of their experiments with various drugs on the rate of $\mathrm{flow}$ of blood through the pulmonary vessels. They find the pulmonary arterioles have no vasomotor nerve supply. 10. W. B. Warrington, M.D., Note on the Ultimate Fate of Ventral Cornual Cells after Section of a number of Posterior Roots. This issue of the journal contains the Proceedings of the Physiological Society on Dec. 12th, 1903, and Jan. 23rd, 1904.

The Journal of Hygiene. Vol. IV., No. 1. January, 1904 London: C. J. Clay and Sons. Price 7s. net.-This number opens with a joint paper on the Chemical Constitation of the Tubercle Bacillus by Dr. William Bulloch and Dr. J. J. R. Macleod, who arrive at the conclusion that the acid- and alcohol-fastness of the tubercle bacillus is due to the presence of an alcohol. Dr. Alexander Edington makes some further remarks on the production of a malarial form of Sonth African horse-sickness, and Dr. E. F. Bashford treats of some fundamental experiments in immunity in a paper which is accompanied by some very instructive plates. Dr. A. E. Boycott and Dr. J. S. Haldane contribute their second paper on Ankylostomiasis in which they discuss the methods of diffusion and the means of diagnosis and treatment of the disease. In the last article Dr. Herbert E. Darham passes in review the several theories which have been held responsible for beri-beri and he arrives at the conclusion that "the appearances and disappearances of beri-beri and the more or less seasonal waves of the disease are not unlike those which are seen in the case of the infective diseases which are met with in this country." Dr. Durham, in fact, thinks that beri-beri may prove to be a communicable disease and that it has to be considered rather in the light of what he calls a "gang" or "institutional" disease than as a "place" or "house" disease.

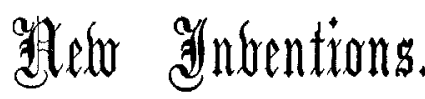

\section{INSTRUMENT FOR THE REMOVAL OF FOREIGN BODIES FROM THE NOSE.}

THE accompanying illustration represents a little instrument which $I$ have designed for the removal of foreign bodies from the nose. The ordinary methods of removal are not always satisfactory and it was after meeting with a difficult case in which an indiarubber teat had been intro. duced into one of the cavities that I sought for some

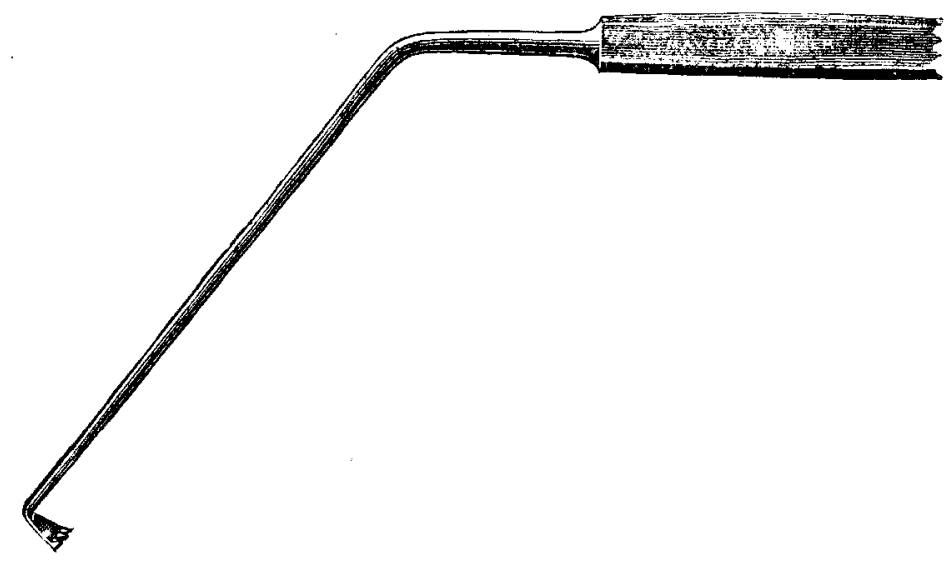

new instrument likely to prove valnable in such circumstances. As will be seen, the end of the instrument is fittened and turned down, this portion being six millimetres in depth and being provided with three small teeth. It can be readily passed into the nose beyond the object to be withdrawn and gentle traction will lead to rapid removal of the foreign body without laceration of the surrounding parts. Rhinoliths may, no doubt, be dealt with in the same way. Messrs. Mayer and Meltzer, of 71 , Great Portlandstreet, London, W., made the instrument for me.

ARTHUR ROBERTS, F.R.C.S. Edin.,

Reading. $\quad$ Surgeon to the Ear, Throat, and Nose D
Royal Berkshire Hospital.

\section{NOTE ON A SIMPLE STERILISABLE BAG FOR} CLOSED ETHER INHALERS.

THE indiarubber bags for Clover's and other ether inhalers are liable to perish unless often used and kept in a warm place, besides not always being easily replaced. Moreover, they will not usually stand repeated or prolonged boiling. I should like to describe a simple home-made article made from jaconet, or still better, from a new waterproof material which can be boiled called "mosetig battist." This is sold in widths of 36 inches and one yard is enough to make four Clover's bags. There are other materials of like make sold -e.g., one called "billroth." The directions for making the bag are as follows. A yard of battist is taken and doubled so that the shiny surface is inside, then the pattern is laid on the battist (using no pins), the bag is cut out, then stitched round its edge, leaving a margin of from one-eighth to onequarter of an inch, and, still keeping the shiny surfaces together, is turned inside out and stitched round again, making a flat seam. Then the bag is inverted and is ready for use. The shiny surfaces seem to adhere along the seam. Bags so made are airtight and watertight and can be used just like rubber ones, than which they are vary much cheaper. The neck, of course, should be made wider than that of a Olover's bag as it will not stretch. A rubber band or piece of string is used to fix the neck to the angle piece of the inhaler. These bags, then, are quickly and easily made at home, are very cheap, will stand sterilising by boiling, and are very lasting. Birmingham. 